\title{
Evaluation of PM in Flanders
}

\author{
M. Bossuyt ${ }^{1}$, C. Matheeussen ${ }^{1} \&$ R. Torfs ${ }^{2}$ \\ ${ }^{\prime}$ Flemish Environment Agency (VMM), Belgium \\ ${ }^{2}$ Flemish institute for technological research (Vito), Belgium
}

\begin{abstract}
The yearly reports on the environment and nature in Flanders (MIRA) ensure the scientific foundations for environmental policy plans. MIRA uses indicators to describe and analyse the environment. Indicators summarise the available knowledge and make it as accessible, as can be to the policy and to the public at large. In putting the indicators in a context of guide values and/or objectives they can help check the policy that is implemented.

Every year about twenty-three themes are discussed following the different links of the DPSIR-chain. This is the causal framework for describing the interactions between society and the environment adopted by the European Environment Agency: Driving forces, Pressures, States, Impacts, and Responses. Every link of the DPSIR-chain is described with reference to one or more indicators. Consequently, there are indicators that record the consequences for and impact on mankind, nature and the economy.

One of the treated themes is dispersion of particulate matter. For this theme we present an overview of the different indicators representing the DPSIR-chain. Since particulate matter is currently suspected to be an important environmental factor causing ill health, we will focus on the indicators concerning human health. Based on significant epidemiological and toxicological evidence of the effects of particulate matter on health, an extensive health impact assessment of PM10 is possible. The information drawn from this impact assessment can be translated into different indicators that are useful in different policy fields. External costs of health effects are appropriate for cost-benefit analyses of policy plans or emission reduction measures. Disability adjusted life years (DALY's) of different health themes make comparison of risks and impacts between disease factors possible and help to make more rational use of resources. Other indicators as attributable cases are helpful in communication with the public.
\end{abstract}




\section{Environmental Health Risk}

\section{Introduction}

The yearly reports on the environment and nature in Flanders (MIRA) ensure the scientific foundations for environmental policy plans.

The task of MIRA is three-fold:

- a description, analysis and assessment of the actual environmental state, described in the yearly MIRA-T reports;

- a description, analysis and assessment of the existing policy, described in the MIRA-BE reports of which the first one is published in 2003;

- a description of the expected development of the environment with both an unchanged and a changed policy, according to a number of scenarios deemed relevant in the five-yearly MIRA-S report.

MIRA gathers fragmented scientific knowledge present in Flanders in different universities, scientific research facilities, administrative services and other organisations. The MIRA-Team of the Flemish Environment agency coordinates these efforts. The authors of the different chapters have the task to rearrange the current knowledge to make it applicable for scientific foundation of the policy. A lector panel also critically reviews every chapter.

MIRA uses indicators to describe and analyse the environment. Indicators summarise the available knowledge and make it as accessible as can be to the policy and to the public at large. In putting the indicators in a context of guide values and/or objectives they can help check the policy that is implemented.

Every year about twenty-three themes are discussed following the different links of the DPSIR-chain. This is the causal framework for describing the interactions between society and the environment adopted by the European Environment Agency: Driving forces, Pressures, States, Impacts, and Responses. Every link of the DPSIR-chain is described with reference to one or more indicators. Consequently, there are indicators that record the consequences for and impact on mankind, nature and the economy.

\section{Driving forces}

The main driving forces that contribute to the emission of particulate matter are the big furnaces (including thermal power stations), heating of buildings, traffic, industrial activities (processes), storage and transhipment and constructions. Natural sources are mainly resuspended particulate matter and sea salt.

\section{Pressure: Emissions of total primary PM}

The emission of total primary particulate matter is decreasing in Flanders since 1996. Traffic is without a doubt the most important source in the year 2001. European standards on cars (Euro3, Euro4,...) and the elimination of more polluting cars without these standards (Euro0) is responsible for a small decrease of exhaust emissions of traffic, despite the increase of the fleet and the increased share of diesel-driven cars. 


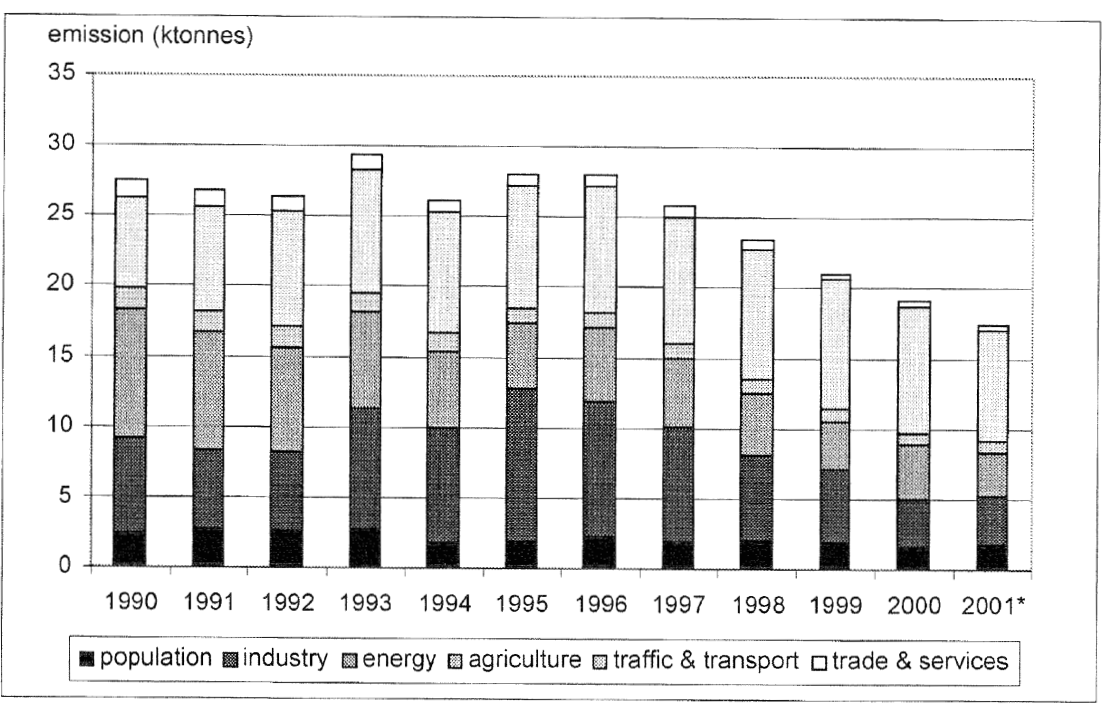

* Preliminary data

Figure 1: Emissions of total primary particulate matter in Flanders (source: [1]).

Industry is responsible for $20.5 \%$ of the emissions. European and Flemish standards for emissions of big furnaces result in an decreasing trend of emissions since 1996 despite the increasing energy use of this sector and thanks to the implementation of new technology and the use of cleaner fuels.

The energy sector has also decreasing emissions the past few years. European guidelines on big furnaces had a great influence on these emissions in particular the increased use of natural gas and the installation of a flue gas desulphurisation unit on one power stations running on coals.

For trades and services the emissions are reduced by a strict policy on waste incineration.

Emissions of agriculture and industry are underestimated. Furthermore the diffuse emissions of traffic (wear of brakes, tires,...) are not included in these data.

The indicator used here, i.e. total primary PM emissions in Flanders, has no immediate connection with PM10-concentrations. Only a fraction of the total primary PM emissions have an aerodynamic diameter smaller then $10 \mu \mathrm{m}$. The concentration in the air is also determined by the presence of PM-precursors, mainly sulphur dioxide $\left(\mathrm{SO}_{2}\right)$, oxides of nitrogen $\left(\mathrm{NO}_{\mathrm{x}}\right)$, some volatile organic compounds (VOC) and ammonia $\left(\mathrm{NH}_{3}\right)$, and is for a large part attributable to emissions in the surrounding countries.

\section{State: air quality}

The Council Directive 1999/30/EC of 22 April 1999 laying down limit values for $\mathrm{SO}_{2}, \mathrm{NO}_{2}$ and $\mathrm{NO}_{\mathrm{x}}, \mathrm{PM} 10$ and lead in the ambient air formulates a number of 


\section{Environmental Health Risk}

limits for PM10 by 2005 and 2010. The objectives for annual average PM10 concentration are copied in the draft of the Flemish Environmental Policy Plan 3 [2]. The European Union still has the possibility of reviewing the 2010 objective when more information about health issues and feasibility of technical measures is available. Possibly objectives for PM2.5 are formulated at the same time.

\subsection{Annual Average PM10-concentration}

Figure 2 illustrates the trend of the annual average PM10 concentration since 1996, and this for all PM10 measuring stations of the telemetric network maintained by the VMM.

An average value has been calculated for industrial, suburban, urban and rural areas. These concentrations give an idea of the long-term exposure of PM10.

The cold winter in 1996 and the cold wave at the beginning of 1997 had an influence on the higher annual average concentrations those years. The highest decrease of concentrations occurred in the suburban and industrial areas in the period 1996-2001. Recently the PM10 concentrations seem to have increased again, but it is too early to speak of a rising trend. The extent of increase of the concentrations is different for each measuring station. The trend found in the emissions is not found in the resulting concentrations, and there are different factors involved to explain the difference. Emissions are not only PM10, a course fraction of particulate matter is also included, and is not found in the $\mathrm{PM}_{10}$ concentrations. Furthermore a part of PM10 in ambient concentrations is secondary formed PM10 and is not included in the emission data. Also unknown sources, weather conditions, import from abroad and resuspension of dust can influence the concentration.

Since 1999 the average concentrations in the four areas remain under the target for $2005\left(40 \mu \mathrm{g} / \mathrm{m}^{3}\right)$. In some individual measuring stations the targets are still exceeded, as in the suburban measuring station in Ruisbroek, en in the industrial measuring station in Evergem. The mediate term target for 2010 $\left(20 \mu \mathrm{g} / \mathrm{m}^{3}\right)$ was nowhere respected. 


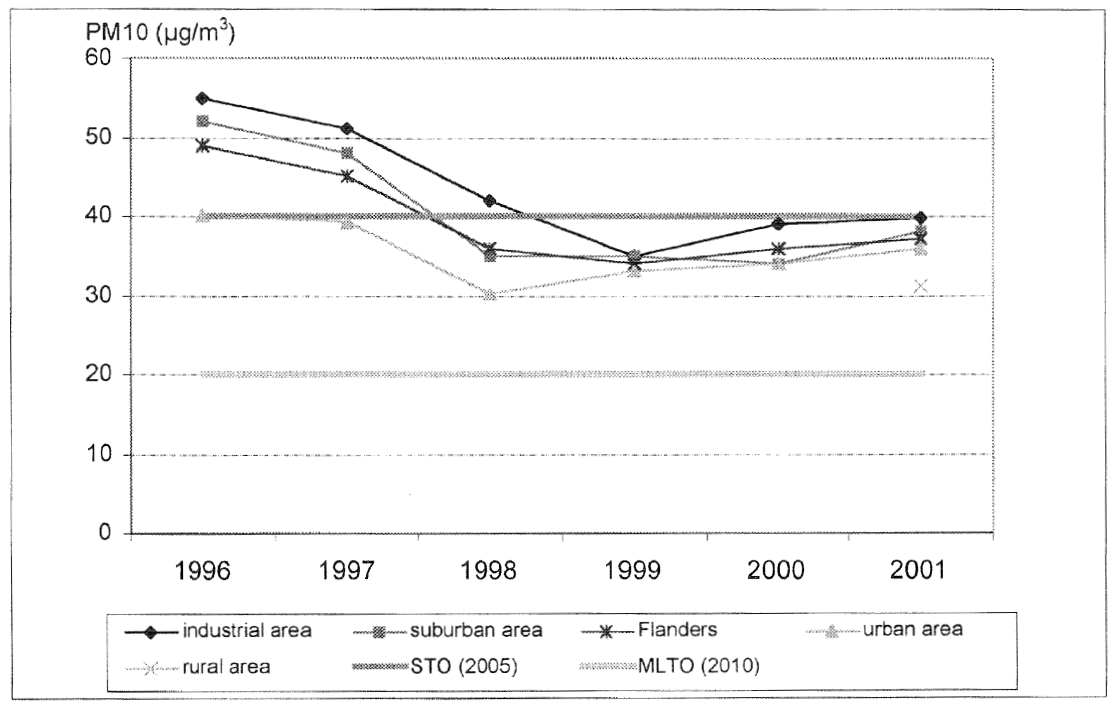

Figure 2: Annual average concentration of PM10 in Flanders [1]

\subsection{Daily Average PM10-concentration}

The daily average PM10-concentration gives an idea of the short-term exposure to peak concentrations of PM10. At 9 of the 15 measuring stations in Flanders more then 35 days a year the daily average PM10-concentration exceeds 50 $\mu \mathrm{g} / \mathrm{m}^{3}$ (target for 2005). The measuring stations with the greatest number of exceeded concentration are for 2001 the industrial measuring station of Evergem and Sint-Kruis-Winkel and the suburban stations of Ruisbroek en Roeselare and in a station in the proximity of chipboard industry at Oostrozebeke. The mediate term target (not more then 7 days exceeding $50 \mu \mathrm{g} / \mathrm{m}^{3}$ ) has not been reached in any station.

\section{Impact: Disability adjusted life years due to PM10 exposure}

In the total burden of disease study the concept of DALY's has been developed to estimate the loss of healthy life years and to compare between regions (Murray, [3], [4]). The indicator combines the loss of life years with the number of years lived with the disease and is expressed in the dimension time. It is the sum of the number of years lost due to death by the disease and the years lived with the disease, considering the gravity of the disease. DALY's can be applied on different health conditions when there are adequate severity weights of the different health effects. S everity weights applicable in Flanders are available (Baert, [5]). DALY's enable a comparison of risks: health risks due to nutrition, habits, accidents or environmental factors can be treated equally and be compared with each other. 


\section{Environmental Health Risk}

Based on the epidemiological and toxicological knowledge of the effects of air pollution on human health, the number of disability adjusted life years (DALY's) and external costs due to PM10 exposure in Flanders has been calculated.

Only for deaths and hospital admittance the necessary data are available in Flanders. Short-term effects are thereby limited to those effects. It should be pointed out that smaller health impacts such as coughing and respiratory complaints can have a substantial part in the total burden of disease and external costs. Hospital admittance and death take an equal part in the total of DALY's of short-term effects.

The long-term effects are calculated according to the health risk assessment described in Künzli [6] and De Hollander [7]. With the current PM10 concentration this leads to a burden of disease due to PM10 of about 25 DALY's per 10000 inhabitants in Flanders. This means that about a quarter to one third of a year is lost, at lifelong exposure to current concentrations of PM10.

Table 1: Quantification of the health effects of PM10 in Flanders in 2001 (95\% confidence interval based on monte carlo analysis) [8]

\begin{tabular}{|c|c|c|}
\hline & DALY's & $\begin{array}{l}\text { external costs } \\
(1000 \text { EUR })\end{array}$ \\
\hline \\
\hline non accidental death & 203 & 48000 \\
\hline \multirow{3}{*}{ hospital admittance due to asthma and COPD } & $(126-291)$ & $(30000-70000)$ \\
\hline & 19 & 3300 \\
\hline & $(6-33)$ & $(1100-5800)$ \\
\hline hospital admittance due to respiratory complaints & 0,8 & 145 \\
\hline ( +65 years $)$ & $(0,4-1,4)$ & $(76.250)$ \\
\hline \multirow[t]{2}{*}{ hospital admittance due to heart complaints } & 42 & 26000 \\
\hline & $(16-73)$ & $(10000-45000)$ \\
\hline \multirow[t]{2}{*}{ use of bronchodilators (children) } & 0,6 & \\
\hline & $(0,2-1,4)$ & $(6-45)$ \\
\hline \multirow[t]{2}{*}{ prevalence of acute bronchitis (children) } & 378 & 11000 \\
\hline & $(171-576)$ & $(5000-17000)$ \\
\hline total short-term effects & 1,1 & 149 \\
\hline per 10000 inhabitants & $(0,7-1,5)$ & $(102-204)$ \\
\hline $\begin{array}{l}\text { Long-term effects } \\
\text { cardiopulmonary death }\end{array}$ & $\begin{array}{r}10100 \\
(3950-17750)\end{array}$ & $\begin{array}{r}1000000 \\
(378000-1700000)\end{array}$ \\
\hline lungcancer death & $\begin{array}{r}3200 \\
(410-5580)\end{array}$ & $\begin{array}{r}306000 \\
(39000-534000)\end{array}$ \\
\hline chronic bronchitis & $\begin{array}{r}2350 \\
(239-3880)\end{array}$ & $\begin{array}{r}846000 \\
(86000-1400000)\end{array}$ \\
\hline $\begin{array}{l}\text { total long-term effects } \\
\text { per } 10000 \text { inhabitants }\end{array}$ & $\begin{array}{r}27 \\
(14-40)\end{array}$ & $\begin{array}{r}3615 \\
(1850-5325)\end{array}$ \\
\hline
\end{tabular}

Starting from the same PM10 concentrations an estimation of the external costs of PM10 air pollution has been made based on the ExternE framework [9]. The environmental damage of particulate matter in Flanders is determined by emissions from Flanders and from abroad. The calculated costs are also dependant on the epidemiological studies on which the DALY calculation is based. Depending on the choice of health endpoints the costs vary between 2.2 
and 5 billion Euro. In the overall impact of air pollution the health effects attributable to particulate matter amounts to about $89 \%$ of the quantifiable external costs of air pollution, excluding greenhouse gasses.

The number of DALY's by short-term effects and long-term effects is not changing significantly (Figure 3). Recent information indicates a clear connection between long-term exposure to PM2.5 and death by heart and lung disease and lung cancer, independent of smoking habits (Pope, [10]). This should lead to caution and more research of possible causes. To deduce clear trends on the impact of decreasing emission of particles, there is a need for more detailed information on exposure of the population e.g. in the proximity of roads with heavy traffic. Research suggests that the exposure to traffic emissions and the ultra-fine fraction of particulate matter are determining factors (Brunekeef, [11]).

(DALY's/10 000 inhabitants)

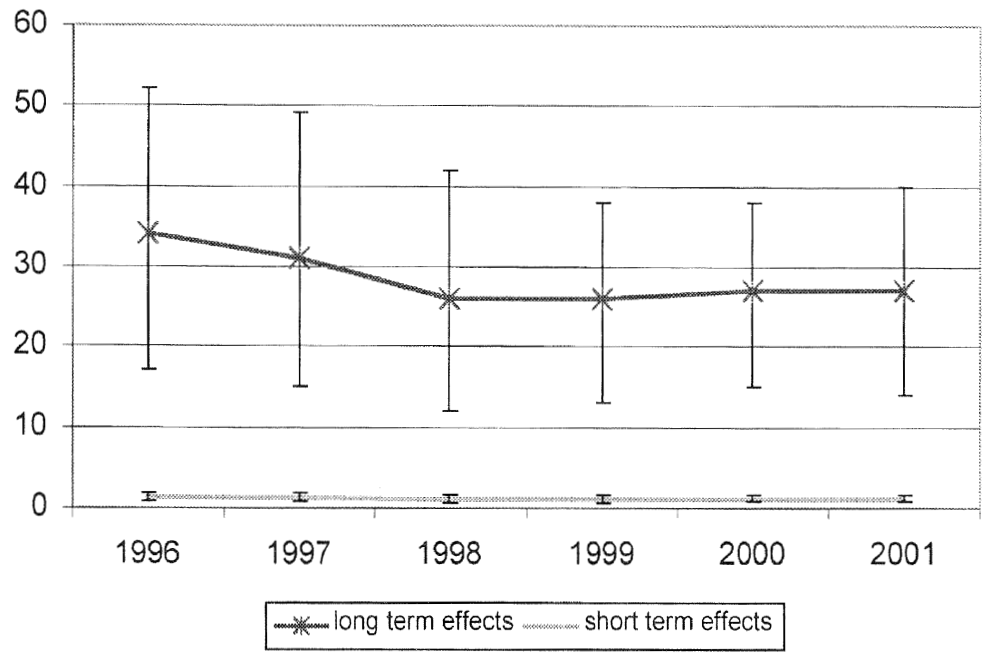

Figure 3: DALY's due to PM10 in Flanders [1]

\section{References}

[1] Torfs R. et al., Verspreiding van zwevend stof (Chapter 2.5). MIRA-T2002 Milieu- en natuurrapport Vlaanderen, ed. Van Steertegem M., Garant: Antwerpen en Apeldoorn, pp.157-162, 2002.

[2] Environmental Policy Plan 2003-2007 (final draft 23/10/2002).

[3] Murray C.J.L., Lopez A.D., The global burden of disease (Published on behalf of the World Health Organisation and the World Bank). Cambridge, MA. Harvard School of Public Health., 1996 
58 Environmental Health Risk

[4] Murray C.J.L., Lopez A.D., On the comparable quantification of health risks: lessons from the global burden of disease study. Epidemiology, 10, pp. 594-605, 1999.

[5] Baert E., Byttebier G, De Backer G., Van Oyen H., Aelvoet W., De Henauw S., (2001) DALYs voor Vlaanderen, PBO/UG/143.

[6] Künzli N., Kaiser R., Medina S., Studnicka M., Chanel O., Filliger P., Herry M., Horak F. Jr., Puybonnieux-Texier V., Quenel P., Schneider J., Seethaler R., Vergnaud J.C., Sommer H., Public health impact of outdoor and traffic-related air pollution: a European assessment. The Lancet, 356, pp. 795-801, 2000.

[7] De Hollander A.E.M. et al., An aggregate public health indicator to represent the impact of multiple environmental exposures., Epidemiology, 10, pp. 606-617, 1999.

[8] Torfs R., Bossuyt M., MIRA Milieu- en natuurrapport Vlaanderen, Achtergronddocument 2002. 2.5 Verspreiding van zwevend stof., Vlaamse Milieumaatschappij, http://www.milieurapport.be , 2002.

[9] European Commission, 1999. Externalities of fuel cycles. European Commission, DG XII, Science, Research and Development, JOULE, ExternE-Externalities of Energy, Vol. 7, Methodology 1998 Update. European Commission, EUR 19083.

[10] Pope et al., Lung cancer, cardiopulmonary mortality, and long-term exposure to fine particulate air pollution, $J A M A, \mathbf{2 8 7 ( 9 )}$, pp. 1132-1141, 2002.

[11] Brunekreef et al., Air pollution from truck traffic and lung function in children living near motorways, Epidemiology, 8(3), pp. 298-303, 1997. 